\title{
Tuning of Structural and Optical Properties of Graphene/ZnO
}

\section{Nanolaminates}

Margarita Baitimirova ${ }^{1}$, Roman Viter ${ }^{2,3}$, Jana Andzane ${ }^{1}$, Arie van der Lee $e^{4}$, Damien Voiry ${ }^{4}$, Igor Iatsunskyi, Emerson Coy, Lina Mikoliunaite ${ }^{3,6}$, Saulius Tumenas ${ }^{3}$, Karol Zateski ${ }^{5}$, Zigmas Balevicius $^{3}$, Ieva Baleviciute ${ }^{3,6}$,Almira Ramanaviciene ${ }^{3,6}$, Arunas Ramanavicius ${ }^{3,6}$, Stefan Jurga ${ }^{5}$, Donats Erts ${ }^{l *}$, Mikhael Bechelany ${ }^{4 *}$

${ }^{1}$ Institute of Chemical Physics, University of Latvia, 19 Raina Blvd., LV 1586, Riga, Latvia

${ }^{2}$ Institute of Atomic Physics and Spectroscopy, University of Latvia, 19 Raina Blvd., LV 1586, Riga, Latvia

${ }^{3}$ State Research Institute Center for Physical Sciences and Technology, Savanoriuave. 231, LT-01108, Vilnius,

Lithuania

${ }^{4}$ European Institute of Membranes, University of Montpellier, Place Eugene Bataillon, 34095, Montpellier, France

${ }^{5}$ NanoBioMedical Centre, Adam Mickiewicz University, 85 Umultowska str., 61-614, Poznan, Poland

${ }^{6}$ Faculty of Chemistry, Vilnius University, 24 Naugarduko, LT-03225, Vilnius, Lithuania

* Corresponding author : mikhael.bechelany@univ-montp2.fr, Phone: +33467149167, Fax: +33467149119

DonatsErts: donats.erts@lu.lv

\section{ABSTRACT}

Zinc Oxide $(\mathrm{ZnO})$ and graphene $(\mathrm{G})$ have been extensively studied because of their unique physical properties. Here, Graphene-Zinc Oxide $(\mathrm{G} / \mathrm{ZnO})$ nanolaminates were fabricated, respectively, 
by chemical vapor deposition and low temperature atomic layer deposition technique. The number of obtained $\mathrm{G} / \mathrm{ZnO}$ layers was tuned from 1 to 11 with a total thickness of $100 \mathrm{~nm}$ for all prepared nanolaminates. The structure, optical properties and interaction between $\mathrm{G}$ and $\mathrm{ZnO}$ were studied by X-ray methods, TEM, AFM, Raman and optical spectroscopy. The obtained results were interpreted and analysed taking into account strain and charge effects of graphene in $\mathrm{G} / \mathrm{ZnO}$ nanostructures. We demonstrate that the bottom graphene used as a substrate stimulated the formation of $\mathrm{ZnO}$ crystalline structure. $\mathrm{n}$-doping of graphene caused by charge transfer from $\mathrm{ZnO}$ to graphene has been detected by blue-shift of G-band of Raman spectra of the nanolaminates. $\mathrm{ZnO}$ photoluminescence intensity was found to be dependent on the number of graphene layers in $\mathrm{G} / \mathrm{ZnO}$ nanolaminate. $\mathrm{n}$-doping of graphene could be tailored by controlling the construction of the $\mathrm{G} / \mathrm{ZnO}$ nanolaminates for variety of applications such as, for example, selective adsorption of the target molecules on graphene surface. Thus, G/ZnO nanolaminates may find applications in optical, bio- and chemical sensors. 


\section{INTRODUCTION}

In the past few years both semiconductors - zinc oxide $(\mathrm{ZnO})$ and graphene $(\mathrm{G}$, semiconductor with zero eV band gap) have been extensively studied because of their unique physical properties. $\mathrm{ZnO}$ is known as n-type semiconductor with good transparency, high electron mobility, wide band gap of $3.37 \mathrm{eV}$, high exciton binding energy of $60 \mathrm{meV}$ and strong luminescence at room temperature. ${ }^{1,2}$ Due to high photo-sensitivity, chemical stability and non-toxicity, $\mathrm{ZnO}$ is perspective material for application in $\mathrm{UV}^{3}$, gas ${ }^{4,5}$ and biological sensors. ${ }^{6,7}$

The sensitivity of $\mathrm{ZnO}$ can be enhanced not only by the decrease of its dimensions down to nanostructures, ${ }^{8}$ but also by its combination with carbon-based nanomaterials (carbon nanotubes, graphene) in composites and hybrid structures. ${ }^{9,}{ }^{10}$ Investigations of single graphene-ZnO interfaces showed that graphene can act as an excellent electron acceptor and transport material for effectively separate photoinduced excitons formed in $\mathrm{ZnO} .{ }^{11}{ }^{12}$ This property makes the combination of graphene$\mathrm{ZnO}$ highly promising for applications in optoelectronic devices, ${ }^{11,13}$ gas ${ }^{14}$ and biological sensors, $,{ }^{12}, 14$ where graphene can act like a high conducting mesh. In its turn, sensor performance strongly depends on resistance of junction interface. ${ }^{15}$

$\mathrm{ZnO}$ thin films can be synthesized using various methods including hydrothermal, ${ }^{16}$ Chemical Vapor Deposition (CVD), ${ }^{17}$ magnetron and RF sputtering, ${ }^{18,19}$ spin-coating, ${ }^{20}$ ultrasonic spray pyrolysis ${ }^{21}$ and atomic layer deposition (ALD) $)^{21-23}$ methods. Among these methods, ALD enables the deposition of high quality and uniform thin films with controlled reaction and growth mechanism at the atomic level and performed at low temperatures $\left(60-100{ }^{\circ} \mathrm{C}\right) .{ }^{22-24}$ We note here that the ability to synthesize ultrathin film at low temperature offered by ALD is important to prevent the interdiffusion of materials. ${ }^{24}$

Graphene can be fabricated by exfoliation from graphite, ${ }^{25}$ reduction of exfoliated graphene oxide, ${ }^{26}$ epitaxial growth using $\mathrm{SiC}$ substrates ${ }^{27}$ and $\mathrm{CVD}$ on a metal catalytic layer $(\mathrm{Cu}, \mathrm{Ni}){ }^{28}$ Due to economic feasibility and easy fabrication, exfoliated graphene and exfoliated reduced graphene oxide have mostly been used for the fabrication of graphene- $\mathrm{ZnO}$ heterostructures. ${ }^{13,14,16,28,29}$ However, the 
exfoliation method produces graphene layers with uncontrollable number of monolayers, limited area of coating and poor electronic properties. On the contrary, the CVD method enables the production of high quality monolayer graphene films with large continuous areas and allows as well the transfer of graphene sheets on arbitrary substrates. In a previous report on graphene-ZnO hybrid structures, CVD graphene was used either as a substrate for $\mathrm{ZnO}$ deposition, i.e., as a bottom layer, ${ }^{30}$ or as a top layer. ${ }^{31}$ To our knowledge, the design of hybrid material composed of "graphene at the bottom and on the top of $\mathrm{ZnO}$ layer", as well as multilayer graphene- $\mathrm{ZnO}$ "sandwich"-type nanostructures (G/ZnO nanolaminates) have not been reported yet. Similarly to previously reported $\mathrm{Al}_{2} \mathrm{O}_{3} / \mathrm{ZnO}$ nanolaminates, ${ }^{32}$ where $\mathrm{Al}_{2} \mathrm{O}_{3}$ layers affected the band gap and photoluminescence of $\mathrm{ZnO}$, influence of graphene on $\mathrm{ZnO}$ properties (crystal growth, photoluminescence and band gap), as well as influence of $\mathrm{ZnO}$ on graphene properties (strain, charging) are expected in $\mathrm{G} / \mathrm{ZnO}$ nanolaminates.

In this study the $\mathrm{G} / \mathrm{ZnO}$ nanolaminates were fabricated by creating alternating $\mathrm{ZnO}$ and graphene layers with total nanolaminate thicknesses of $100 \mathrm{~nm}$, which enables structural and optical measurements well above the noise level. ${ }^{23}$ The fabrication of nanostructures started with the graphene as a bottom layer of a nanolaminate, promoting formation of hexagonal wurtzite structure of $\mathrm{ZnO}$ from its first deposited atomic layers. In the next steps $\mathrm{ZnO}$ interlayers of different thicknesses were alternated with graphene monolayers. The graphene was chosen also as a top layer of the nanolaminate as it is compatible with most organics, bio- and gas molecules. Therefore, fabricated G/ZnO nanolaminates offer perspective for wide range of applications such as optoelectronic devices, sensors and catalysts.

\section{MATERIALS AND METHODS}

$\mathrm{G} / \mathrm{ZnO}$ nanolaminates were deposited on $\mathrm{Si}$ substrates with native silicon oxide $\left(\mathrm{SiO}_{2}\right)$ layer. The $\mathrm{Si} / \mathrm{SiO}_{2}$ substrates were ultrasonically pre-cleaned with acetone, ethanol and deionized water for 15 min. Monolayer graphene films were synthesized by copper-catalysed low-pressure CVD as reported elsewhere ${ }^{33}$ using a reactor (First Nano Easy tube 101). Graphene monolayers were 
transferred to the desired substrate by polymer-assisted transfer technique ${ }^{34}$ followed by the deposition of $\mathrm{ZnO}$ layer over it (Figure 1). $\mathrm{ZnO}$ layers of the thickness of 10, 25, 50 and $100 \mathrm{~nm}$ were synthesized by ALD method using home-made ALD reactor ${ }^{35}$ at the same conditions as described elsewhere. ${ }^{23}$ In the next step, graphene monolayer was transferred onto the deposited $\mathrm{ZnO}$ layer. The sequential deposition of $\mathrm{ZnO}$ layer and graphene transfer was repeated until multilayer structure with a total thickness of $100 \mathrm{~nm}$ was obtained. For the comparison, $100 \mathrm{~nm}$ thick pure $\mathrm{ZnO}$ thin film was deposited on Si substrate using the same ALD conditions. Further in the text the samples are named by the formula $G_{x L} Z n O_{y n m}$, where $x$ is the number of graphene layers and $y$ is the thickness in nanometers of $\mathrm{ZnO}$ single layer in multilayer structure.

The surface topography of fabricated $\mathrm{G} / \mathrm{ZnO}$ nanolaminates was characterized using atomic force microscopy (AFM, Asylum 3D). The morphology and structure of G/ZnO nanolaminates were studied by X-ray reflectivity (XRR, Bruker D5000), X-ray diffraction (XRD, Bruker D5000 with $\mathrm{CuK} \alpha$ radiation, using the Bragg-Brentano symmetric configuration) and high-resolution transmission electron microscopy (HRTEM, JEOL ARM 200F (200 kV). The cross sections and lamellas for TEM investigations were prepared by focused ion beam milling (JEOL JIB-4000) by the method described elsewhere. ${ }^{36}$ The Raman spectra were obtained using Witek ALFA300R Raman spectrometer with 532 $\mathrm{nm}$ excitation laser source. Optical properties of $\mathrm{G} / \mathrm{ZnO}$ nanolaminates were analyzed by UV-VIS reflectance (Shimadzu UV-3600) and photoluminescence (Edinburg Instruments FLS 980) spectroscopy. The excitation of luminescence was performed by a Xe lamp line, centred at $280 \mathrm{~nm}$. The band gap of $\mathrm{ZnO}$ was calculated in absorption edge region according to the procedure, described elsewhere. ${ }^{37}$

\section{RESULTS AND DISCUSSION}

In order to understand the effect of graphene incorporation on $\mathrm{G} / \mathrm{ZnO}$ properties, $\mathrm{G} / \mathrm{ZnO}$ nanolaminates were fabricated by alternating $\mathrm{ZnO}$ and graphene layers with total nanolaminate thickness of $100 \mathrm{~nm}$. The fabrication of nanostructures started with graphene as 
a bottom layer of the nanolaminate. In the next steps $\mathrm{ZnO}$ interlayers of different thicknesses were alternated with graphene monolayers. Graphene was chosen also as a top layer of the nanolaminate (Figure 1). The samples are named by the formula $G_{x L} Z n O_{y n m}$, where $x$ is number of graphene layersandy is the thickness in nanometers of $\mathrm{ZnO}$ single layer in multilayer structure.

High-resolution cross-section TEM images confirmed the sequence of alternating $\mathrm{ZnO}$ and graphene layers throughout all fabricated nanolaminates (Figure 2 a-d). The native silicon oxide $\left(\mathrm{SiO}_{2}\right)$ layer on the silicon surface was about $2 \mathrm{~nm}$ thick (Figure 2a inset). The total thickness of all obtained G/ZnO nanolaminates was about $100 \mathrm{~nm}$. From TEM images, it can be seen that the individual $\mathrm{ZnO}$ layers were of constant thickness and well reproducible. However, the increase of a number of graphene interlayers and accordingly decrease of $\mathrm{ZnO}$ interlayer thickness results in worsening of layers smoothness (Figure $2 \mathrm{c}, \mathrm{d}$ ), most likely related to increase of nanolaminate surface roughness.

The high resolution TEM analysis of G/ZnO nanolaminates showed the presence of (100), (002), (101), (110) and (103) fringes in the selected area of $\mathrm{ZnO}$ layer (Figure $2 \mathrm{e}, \mathrm{f}$ ). The fringe separation of $0.275 \mathrm{~nm}$ determined from the HRTEM image (Figure $2 \mathrm{e}$ ) corresponds to (100) plane of wurtzite crystal structure of $\mathrm{ZnO}$.

Obtained XRD spectra of the $\mathrm{ZnO}$ layers of $\mathrm{G} / \mathrm{ZnO}$ nanolaminates (Figure 3 a) demonstrated the diffraction peaks at $2 \theta=31.80^{\circ}, 34.54^{\circ}, 36.16^{\circ}$ and $56.32^{\circ}$, corresponding to (100), (002), (101) and (110) reflection planes of hexagonal wurtzite structure of $\mathrm{ZnO}$ respectively ${ }^{8}$ in perfect agreement with TEM results. The peak related to (103) plane of $\mathrm{ZnO}$ crystal presented in FFT image (Figure $2 \mathrm{f}$ ) was not observed as it was out of XRD measurement range (diffraction peak position of $(103)$ plane is at $\left.2 \theta=62.7^{\circ}\right) .{ }^{38}$ Peak observed at $2 \theta=32.95^{\circ}$ is corresponding to (004) reflection plane of silicon substrate. 
The above peaks were observed in XRD patterns of all $\mathrm{G} / \mathrm{ZnO}$ nanolaminates, indicating their high crystalline structure. No characteristic peaks for any impurities as, for example, PMMA, $\mathrm{FeCl}_{3}, \mathrm{Cu}$, etc. residuals from graphene transfer process, were observed. Calculated from XRD spectra $\mathrm{ZnO}$ lattice constants were equal to $a=0.325 \mathrm{~nm}$ and $c=0.519 \mathrm{~nm}$, which fits perfectly with $\mathrm{ZnO}$ crystal lattice parameters. ${ }^{38}$ The lattice spacing between the atom stacks calculated from the FFT image of a selected area of $\mathrm{ZnO}$ interlayer were in good correlation with XRD data (Figure $2 \mathrm{f}$ (inset) and Figure 3a). No significant changes of $\mathrm{ZnO}$ lattice parameters were observed with decreasing of thickness of $\mathrm{ZnO}$ interlayers in the nanolaminates, which is in good correlation with previous report on lattice parameters of ALD deposited $\mathrm{ZnO}$ thin films of different thicknesses. ${ }^{23}$

No amorphous-to-crystalline growth transition of $\mathrm{ZnO}$ was observed in contradiction with previously reported $\mathrm{ALD}$ deposited on $\mathrm{Si} / \mathrm{SiO}_{2}$ substrates $\mathrm{ZnO}$ thin films ${ }^{23}$ and $\mathrm{Al}_{2} \mathrm{O}_{3} / \mathrm{ZnO}$ nanolaminates, ${ }^{32}$ where the amorphous-to-crystalline transition of $\mathrm{ZnO}$ occurred for the layers with thickness larger than $25 \mathrm{~nm}$ and $10 \mathrm{~nm}$ respectively. As it can be seen from the obtained G/ZnO nanolaminates XRD and HRTEM data, even the thinnest (10 $\mathrm{nm}) \mathrm{ZnO}$ layers have a crystalline nature (Figure $3, \mathrm{G}_{11 \mathrm{~L}} \mathrm{ZnO}_{10 \mathrm{~nm}}$, Figure $2 \mathrm{f}$ ).

From the intensities of the diffraction peaks in XRD spectra (Figure 3a, b) it can be seen that for the 10 and $25 \mathrm{~nm}$ thick $\mathrm{ZnO}$ interlayers, the [002] crystal growth direction is dominating, while with an increase of $\mathrm{ZnO}$ interlayer thickness up to $50 \mathrm{~nm}$, as well as for the $100 \mathrm{~nm}$ thick $\mathrm{ZnO}$ thin film deposited on $\mathrm{Si} / \mathrm{SiO}_{2}$ substrate, the [100] and [101] growth directions significantly dominate over [002] and [110] directions. Presumably, the graphene sublayers promote growth of $\mathrm{ZnO}$ crystalline transition layer in [002] direction, which is attributed to very low $(<3 \%)$ mismatch between the graphene and the $\mathrm{ZnO}(002)$ hexagonal lattices. ${ }^{39}$ With the increase of $\mathrm{ZnO}$ interlayer thickness, [100] and [101], considered as fast 
$\mathrm{ZnO}$ growing directions are prevailing. ${ }^{39}$ These results suggest that the advantageous role of graphene as template in the formation of highly crystalline $\mathrm{ZnO}$.

The AFM images of the surface of $100 \mathrm{~nm}$ thick $\mathrm{G} / \mathrm{ZnO}$ nanolaminates with various numbers of graphene interlayers indicate that as the number of graphene interlayers increases, the morphology of the top graphene surface became rougher (Figure 4a,b). The calculated root mean square (RMS) roughness of the surface of $\mathrm{G} / \mathrm{ZnO}$ nanolaminates from AFM data showed linear increase versus the number of graphene layers in the nanolaminates (Figure 4 c). The explanation may be related to the fact that every next graphene layer follows the morphology of the $\mathrm{ZnO}$ sublayer surface. The RMS estimation does not account for possible artifacts (strain/elastic resistance of graphene) that might be caused by the pressure of AFM probe during the surface scanning.

The increase of the surface roughness of the $\mathrm{G} / \mathrm{ZnO}$ nanolaminates as determined is supported by the X-ray reflectivity data (Figure 5). In comparison with pure $\mathrm{ZnO}$ thin film $\left(\mathrm{G}_{0 \mathrm{~L}} \mathrm{ZnO}_{100 \mathrm{~nm}}\right)$, the number of Kiessig fringes was significantly reduced when increasing number of graphene layers $\left(\mathrm{G}_{2 \mathrm{~L}} \mathrm{ZnO}_{100 \mathrm{~nm}}, \mathrm{G}_{3 \mathrm{~L}} \mathrm{ZnO}_{50 \mathrm{~nm}}, \mathrm{G}_{5 \mathrm{~L}} \mathrm{ZnO}_{25 \mathrm{~nm}}\right)$ and then disappeared for $\mathrm{G}_{11 \mathrm{~L}} \mathrm{ZnO}_{10 \mathrm{~nm}}$, indicating an increase of the $\mathrm{G} / \mathrm{ZnO}$ nanolaminate surface roughness as well as the interfacial roughness. The $\mathrm{ZnO}$ layer without any graphene top or bottom layer $\left(\mathrm{G}_{0 \mathrm{~L}} \mathrm{ZnO}_{100 \mathrm{~nm}}\right)$ showed nearly perfect Kiessig fringes, which can be modelled using Parrat's recursive formula ${ }^{40}$ for $\mathrm{X}$-ray reflectivity. The thickness of $\mathrm{ZnO}$ layer calculated from the Kiessig fringes was $99.7 \mathrm{~nm}$ in perfect agreement with the TEM data. The surface roughness of $1.6 \mathrm{~nm}$ was rather close to the RMS surface roughness of $1.9 \mathrm{~nm}$, which was determined by AFM. The gradual extinction of the Kiessig fringes, which is apart from the rather large surface roughness, for larger incident angles - is also observed due to the roughness at the buried interface between the substrate and the film $(0.8 \mathrm{~nm})$. 
We note here that due to the gas barrier properties of the graphene CVD thin films, ${ }^{41}$ the porosity of our thin films could not be evaluated using common techniques such as Surface acoustic wave (SAW) /BET technique or Ellipsometry Porosimetry.

The reflectivity curve of $\mathrm{G} / \mathrm{ZnO}$ nanolaminates with two graphene layers $\mathrm{G}_{2 \mathrm{~L}} \mathrm{ZnO}_{100 \mathrm{~nm}}$ showed some short-period Kiessig fringes at very small angles due to the thickness of the $\mathrm{ZnO}$ layer and a long-period fringe with a (first) minimum at $2 \theta=0.9$. Although these longperiod Kiessig fringes at very small angles could be attributed to the bottom graphene layer, they are more coming from the native silica layer of the substrate (Figure 5). The same longperiod fringe was seen slightly shifted to larger angles in the reflectivity curve of nanostructures with three graphene layers $\mathrm{G}_{3 \mathrm{~L}} \mathrm{ZnO}_{50 \mathrm{~nm}}$. The fringes between $2 \Theta=0.5-0.9^{\circ}$ correspond to the $50 \mathrm{~nm}$ thick $\mathrm{ZnO}$ interlayers and fringes below $2 \Theta=0.5^{\circ}$ appeared due to the total thickness of the $\mathrm{G} / \mathrm{ZnO}$ multilayer nanostructure. The reflectivity curve of $\mathrm{G} / \mathrm{ZnO}$ nanostructures with five graphene layers $\mathrm{G}_{5 \mathrm{~L}} \mathrm{ZnO}_{25 \mathrm{~nm}}$ showed different fringe periodicities and did not allow to identify the thickness of $\mathrm{ZnO}$ interlayers. The reflectivity curve of G/ZnO nanostructures with eleven graphene layers $\mathrm{G}_{11 \mathrm{~L}} \mathrm{ZnO}_{10 \mathrm{~nm}}$ cannot be interpreted qualitatively or quantitatively because of its very high RMS surface roughness (Figure 4).

The top graphene layer cannot be detected in the reflectivity curves, because the RMS surface roughness of $\mathrm{G} / \mathrm{ZnO}$ nanolaminates is much larger than the supposed thickness of the graphene layer. Additionally it is worth noting that because of the quenching of the Kiessig fringes, caused by the relatively high surface and interfacial roughness of $\mathrm{G} / \mathrm{ZnO}$ nanolaminates, the reflectivity curves of all fabricated $\mathrm{G} / \mathrm{ZnO}$ structures cannot be analyzed quantitatively, but only qualitatively.

In order to evaluate possible strain and charging effects of graphene in G/ZnO nanolaminates, the Raman spectra of the fabricated structures were investigated (Figure 6a). 
Two intensive peaks at $1583 \mathrm{~cm}^{-1}$ and $2671 \mathrm{~cm}^{-1}$, corresponding to the $\mathrm{G}$ band induced by the vibration of $\mathrm{sp}^{2}$-hybridized carbons and to the $2 \mathrm{D}$ band of second-order process induced Raman feature, respectively, ${ }^{42}$ were observed in all the obtained spectra of the G/ZnO nanolaminates. Both $\mathrm{G}$ and $2 \mathrm{D}$ peaks were sharp, indicating that no oxidation of graphene to graphene oxide ${ }^{43}$ occurred during the formation of ALD ZnO layers and thus suggesting that the high quality of graphene is largely preserved.

The ratio of intensities of the $2 \mathrm{D}$ band to the $\mathrm{G}$ band $\left(\mathrm{I}_{2 \mathrm{D}} / \mathrm{I}_{\mathrm{G}}\right)$ of single $\mathrm{CVD}$ graphene layers used for the $\mathrm{G} / \mathrm{ZnO}$ nanolaminates fabrication was above 2 (see Table $\mathbf{1}, \mathrm{G}_{1 \mathrm{~L}} \mathrm{ZnO}_{0 \mathrm{~nm}}$ ), confirming the monolayer structure of this graphene. ${ }^{44}$ The observed low intensity of D peak at $1350 \mathrm{~cm}^{-1}$ in this spectrum (Figure 6a, Table 1) indicated the presence of insignificant amount of structural defects in the monolayer, which is typical for CVD-grown on $\mathrm{Cu}$ substrate graphene. ${ }^{45}$ When increasing the number of graphene interlayers in the nanolaminates, the $\mathrm{I}_{\mathrm{D}} / \mathrm{I}_{\mathrm{G}}$ ratio moderately increased from 0.1 for a single graphene monolayer up to $\sim 0.22$ for the $\mathrm{G} / \mathrm{ZnO}$ nanolaminates containing from 2 to 11 graphene layers regardless the number of the graphene layers in the nanolaminate (Table 1). Thereby, in contradiction with sputtering techniques, where significant increase in the $\mathrm{I}_{\mathrm{D}} / \mathrm{I}_{\mathrm{G}}$ peak intensity ratio up to 1 is typically observed after $\mathrm{ZnO}$ deposition on the graphene substrate, ${ }^{46}$ the ALD deposition of the $\mathrm{ZnO}$ on graphene surface does not induce severe structural damage in it.

The $\mathrm{I}_{2 \mathrm{D}} / \mathrm{I}_{\mathrm{G}}$ ratio in the Raman spectra of $\mathrm{G} / \mathrm{ZnO}$ nanolaminates decreased from 2.68 for the nanolaminate containing two graphene layers $\mathrm{G}_{2 \mathrm{~L}} \mathrm{ZnO}_{100 \mathrm{~nm}}$ down to 1.33 and 1.20 for $\mathrm{G}_{32} \mathrm{ZnO}_{50 \mathrm{~nm}}$ and $\mathrm{G}_{5 \mathrm{~L}} \mathrm{ZnO}_{25 \mathrm{~nm}}$ structures containing 3 and 5 graphene layers, respectively, and further down to 0.87 for the $\mathrm{G}_{11 \mathrm{~L}} \mathrm{ZnO}_{10 \mathrm{~nm}}$ nanolaminate containing 11 graphene layers (Figure 6 a-c, Table 1). These changes in $I_{2 D} / I_{G}$ intensity ratio may be related to such processes occurring in graphene layers of nanolaminates as charging ${ }^{47}$ and/or mechanically induced strain. ${ }^{48}$ However, the typical redshifts for uniaxial or biaxial graphene strain of either $\mathrm{G}$ or 
2D peaks by $30-50 \mathrm{~cm}^{-1}$ per $0.5 \%$ of $\operatorname{strain}^{48}$ were not observed. This suggests that graphene interlayers in the $\mathrm{G} / \mathrm{ZnO}$ nanolaminates do not experience significant strain, and the changes in positions and intensity ratios of $\mathrm{G}$ and $2 \mathrm{D}$ peaks are mostly related to graphene charging. In spite of absence of the significant damage, the minor strain of graphene may take place in $\mathrm{G} / \mathrm{ZnO}$ nanolaminates. The first layer of graphene of all prepared structures may have insignificant strain due to van der Waals interaction between the graphene and silicon substrate during transfer. The next transferred graphene layers of $\mathrm{G} / \mathrm{ZnO}$ nanolaminates may be exposed to strain forming from van der Waals force existing at the graphene- $\mathrm{ZnO}(002)$ interface of $\mathrm{ZnO}$-graphene hybrid structures ${ }^{39}$ that may result in graphene strain due to lattices mismatch, as well as to the increase of roughness of the nanolaminates (Figure 4).

The evaluation of G-band position of nanolaminates showed that it blue-shifts with the increase of number of graphene interlayers and respectively decreases of thickness of $\mathrm{ZnO}$ interlayers (Figure 6 a,b,c). Blue-shift of G-band is indicative for the graphene charge. ${ }^{49}$ As in $\mathrm{ZnO}$-graphene hybrid structures, the electron transfer occurs from $\mathrm{ZnO}$ to graphene as a result of the difference in their work functions, ${ }^{39}$ the above changes in Raman spectra of G/ZnO nanolaminates may be attributed to the negative charge of graphene by electron transfer from $\mathrm{ZnO}$ layer. Presumably, this electron transfer from $\mathrm{ZnO}$ to graphene results in the formation of depletion layer in $\mathrm{ZnO}$ near the graphene surface, and facilitates accumulation of holes in it. For quantifying graphene charge in the $\mathrm{G} / \mathrm{ZnO}$ nanolaminates, the estimation of concentration of excess electrons per graphene layer was performed based on data reported on interdependence between Raman shift of G-band and the increase of concentration of electrons in monolayer graphene. ${ }^{47}$ It was found that the charge per graphene layer linearly decreases with the increase of number of graphene layers and respectively with decrease of thickness of $\mathrm{ZnO}$ interlayers (Figure $6 \mathrm{c}$ ). The reason for graphene charge to decrease may be related to the interaction and the overlapping of $\mathrm{ZnO}$ depletion layers with the decrease of 
$\mathrm{ZnO}$ interlayer thickness, as well as to the change of defect concentration in $\mathrm{ZnO}$ interlayers related to change of prevailing crystallographic $\mathrm{ZnO}$ growth directions with the decrease of interlayer thickness (Figure 3), and requires further clarification. However, this linear dependence of graphene charge on number of graphene layers in $\mathrm{G} / \mathrm{ZnO}$ nanolaminates may be useful in charge-related applications, for example, for tuning graphene charge by varying the number of graphene interlayers in the nanolaminates for selective adsorption of positive charged target molecules on the graphene surface.

The number of graphene interlayers and thickness of $\mathrm{ZnO}$ layers in $\mathrm{G} / \mathrm{ZnO}$ nanolaminates has strong influences on their optical properties. The shift of $\mathrm{ZnO}$ absorption edges from 360 up to $400 \mathrm{~nm}$ is clearly seen on reflectance spectra recorded for different $\mathrm{G} / \mathrm{ZnO}$ nanolaminates (Figure 7a). The shift of absorption edges of $\mathrm{G} / \mathrm{ZnO}$ nanolaminates relative to absorption edge position of pure $\mathrm{ZnO}$ may be related to the formation of optically active defects at the graphene- $\mathrm{ZnO}$ interface ${ }^{50}$ and $\mathrm{ZnO}$ grain boundaries. The band gap of $\mathrm{G} / \mathrm{ZnO}$ nanolaminates was calculated from the assumption that the reflectance in the absorption edge is related to the band gap values due to the following equations ${ }^{23}$ :

$$
\begin{aligned}
& D=\ln \left(\frac{100}{R}\right) \\
& (D \cdot h v)^{2} \sim\left(h v-E_{g}\right)
\end{aligned}
$$

Where $\mathrm{R}, \mathrm{D}, \mathrm{hv}$ and $\mathrm{E}_{\mathrm{g}}$ are reflectance, optical density, photon energy and band gap, respectively. The $E_{\mathrm{g}}$ values were calculated from the intersection of linear part of the curve with hv-axis. The fitting was performed automatically using Origin 7.0 software (Figure 7b). The obtained band gap values determined from the reflectance spectra of $\mathrm{ZnO}$ decrease with the increase of the number of graphene interlayers and the decrease of thickness of $\mathrm{ZnO}$ interlayers in nanolaminates from the initial value of $3.42 \mathrm{eV}$, obtained for pure $\mathrm{ZnO}$ thin film, down to value of $3.10-3.13 \mathrm{eV}$ for nanolaminates containing 5 and more graphene layers 
respectively (Figure 7c). The levelling of the band gap at these values may be related to the domination of $\mathrm{ZnO}$ [002] crystallographic growth direction over other directions at $\mathrm{ZnO}$ interlayer thicknesses below $25 \mathrm{~nm}$ as confirmed by XRD data (Figure 3), which may reduce the concentration of optically active defects.

In the photoluminescence (PL) spectra of G/ZnO nanolaminates (Figure 8a), the peaks with maximum at $\sim 3.3 \mathrm{eV}(375 \mathrm{~nm})$ related to excitation transitions in $\mathrm{ZnO}^{8,23}$ were observed for all samples. Peaks related to deep level transitions at energies about $2.4-2.5 \mathrm{eV}$ (oxygen and zinc vacancies and zinc interstitials), ${ }^{51}$ as well as at $2.0 \mathrm{eV}$, related to interstitial oxygen in $\mathrm{ZnO}$ films ${ }^{51}$ were not observed for both $\mathrm{ZnO}$ thin film deposited on $\mathrm{SiO}_{2}$ surface and for $\mathrm{G} / \mathrm{ZnO}$ nanolaminates. From the Figure 8 it is clearly seen that the intensity of PL signals decreased with the increase of number of graphene layers and the corresponding decrease of the thickness of $\mathrm{ZnO}$ interlayers in the $\mathrm{G} / \mathrm{ZnO}$ nanolaminates. PL emission may be quenched because of several reasons such as negative charge of graphene surface, with concomitant screening effect in graphene, ${ }^{52}$ transfer and trapping of photo-excited electrons in graphene, ${ }^{11,}$ 12, 39 and similarly to $\mathrm{ZnO} / \mathrm{Al}_{2} \mathrm{O}_{3}$ nanolaminates the increase of the total depletion regions relative to total thickness of $\mathrm{ZnO}(100 \mathrm{~nm})$ when decreasing the $\mathrm{ZnO}$ layer thickness ${ }^{32,}{ }^{50}$. These factors result in the decrease of exciton radiative recombination compared to nonradiative processes in the $\mathrm{G} / \mathrm{ZnO}$ nanolaminates with the increase of the number of graphene interlayers and the decrease of thickness of $\mathrm{ZnO}$ interlayers. The presumable thickness of $\mathrm{ZnO}$ layer with $100 \%$-quenched PL near the single surface of a graphene interlayer was estimated by empirical linearization of PL luminescence intensity as function of summed all quenched $\mathrm{ZnO}$ layer thicknesses in the $\mathrm{G} / \mathrm{ZnO}$ nanolaminates. The closest to linear curve was obtained assuming that the thickness of a $\mathrm{ZnO}$ layer with quenched PL was $10 \mathrm{~nm}$ near every graphene/ZnO interface (Figure $8 \mathrm{~b}$ ). However, as it can be seen from the Figure $8 \mathrm{a}-\mathrm{b}, \mathrm{PL}$ signals are still detected when the presumed total thickness of $\mathrm{ZnO}$ layers in between two 
graphene layers is $10 \mathrm{~nm}$ (Figure $8 \mathrm{~b}$, point $\mathrm{G}_{11 \mathrm{~L}} \mathrm{ZnO}_{10 \mathrm{~nm}}$ ). As a consequence, it can be concluded that PL quenching mechanism in the nanolaminates may not be only based on the dimension of architecture and thus a more complex model is required to fully understand the optical properties of such graphene/ZnO layered films.

\section{CONCLUSION}

In summary, new nanomaterials of $\mathrm{G} / \mathrm{ZnO}$ nanolaminates have been developed and investigated. Combination of CVD and ALD offers a precise control of the thickness and composition of the films. The number of alternating graphene and $\mathrm{ZnO}$ interlayers and the thickness of $\mathrm{ZnO}$ interlayers influenced the structure and the optical properties of the fabricated nanolaminates. During the ALD deposition of $\mathrm{ZnO}$ nanolayers, the bottom graphene used as a substrate stimulated the formation of $\mathrm{ZnO}$ crystalline structure, thus avoiding formation of amorphous transition layer between the graphene and the crystalline $\mathrm{ZnO}$ thin film. ${ }^{32,} 50,53,54 \mathrm{We}$ found that ALD deposition of $\mathrm{ZnO}$ thin films on surface of graphene layers did not introduce severe structural damage. Minor strain and charge transfer from $\mathrm{ZnO}$ to graphene were observed in fabricated $\mathrm{G} / \mathrm{ZnO}$ nanolaminates. The charge transfer resulted in negative charging of graphene as observed by blue-shift of G-band of Raman spectra of the nanolaminates. These results are meaningful for exploration of devices based on Graphene and $\mathrm{ZnO}$ films and the conclusion obtained in this study could be commonly used for other Graphene/metal oxide nanolaminates. The $\mathrm{ZnO}$ PL intensity was found to be dependent on the number of graphene layers in $\mathrm{G} / \mathrm{ZnO}$ nanolaminate. Presumably, the underlying reason for the PL decrease is the partial suppression of radiative recombination occurring at graphene- $\mathrm{ZnO}$ interface. The tuning of the graphene charge together with the $\mathrm{ZnO} \mathrm{PL}$ intensity in $\mathrm{G} / \mathrm{ZnO}$ nanolaminates has prospects in applications for FET gate, 
biosensors, chemical sensors and catalysts. The variable negative charging of graphene layers might provide a selective adsorption of the positive charged target molecules on its surface. Optical properties of $\mathrm{G} / \mathrm{ZnO}$ nanolaminates can be used in optical transducer during sensor/biosensor development. Finally, multilayer structure synthesized by alternating graphene and metal oxide layers could be very attractive for a wide range of applications such as the realization of mid-infrared graphene hyperbolic metamaterials, ${ }^{55}$ encapsulation materials with high impermeability to moisture and $a^{56}{ }^{56}$ or to improve the thermal conductivity of polymers. ${ }^{57}$ These new properties of the $\mathrm{G} / \mathrm{ZnO}$ nanolaminates materials are under investigations.

ACKNOWLEDGEMENTS:This work was supported by Latvian National Research program IMIS-2 and partially supported by the EU under BIOSENSORS-AGRICULT, Contract PIRSES-GA-2012-318520 'Development of Nanotechnology-based Biosensors for Agriculture', Scientific grant of The Research Council of Lithuania (application registration No. VIZ-TYR-126, 2015), by Campus France (PHC GILIBERT 2015, PROJET Nº 32978PG and PHC OSMOSE 2016, PROJET N $\mathrm{N}^{\circ}$ 35056UB) and by the ANR project ANR-14-CE070011 "BONALD”. Z.B., I.B. and A.R. research was funded by a grant (No. TAP LZ-3/2015) from the Research Council of Lithuania. K.Z. acknowledges support from Polish National Science Center Grant DEC-2014/15/B/ST3/02927.

\section{REFERENCES}

1. Ozgur, U.; Alivov, Y. I.; Liu, C.; Teke, A.; Reshchikov, M. A.; Dogan, S.; Avrutin, V.; Cho, S. J.; Morkoc, H., A Comprehensive Review of ZnO Materials and Devices. J. Appl. Phys. 2005, 98, 041301. 
2. Bechelany, M.; Amin, A.; Brioude, A.; Cornu, D.; Miele, P., ZnO Nanotubes by Template-Assisted Sol-Gel Route. J. Nanopart. Res. 2012, 14, 980.

3. Abou Chaaya, A.; Bechelany, M.; Balme, S.; Miele, P., ZnO 1D Nanostructures Designed by Combining Atomic Layer Deposition and Electrospinning for UV Sensor Applications. J. Mater. Chem. A 2014, 2, 20650-20658.

4. Ahn, M. W.; Park, K. S.; Heo, J. H.; Kim, D. W.; Choi, K. J.; Park, J. G., On-Chip Fabrication of ZnO-Nanowire Gas Sensor with High Gas Sensitivity. Sens. Actuator B-Chem. 2009, 138, 168-173.

5. Drobek, M.; Kim, J.-H.; Bechelany, M.; Vallicari, C.; Julbe, A.; Kim, S. S., MOFBased Membrane Encapsulated ZnO Nanowires for Enhanced Gas Sensor Selectivity. ACS Appl. Mater. Interfaces 2016, 8, 8323-8328.

6. $\quad$ Viter, R.; Khranovskyy, V.; Starodub, N.; Ogorodniichuk, Y.; Gevelyuk, S.; Gertnere, Z.; Poletaev, N.; Yakimova, R.; Erts, D.; Smyntyna, V.; et al., Application of Room Temperature Photoluminescence From ZnO Nanorods for Salmonella Detection. IEEE Sens. J. 2014, 14, 2028-2034.

7. Tereshchenko, A.; Bechelany, M.; Viter, R.; Khranoyskyy, V.; Smyntyna, V.; Starodub, N.; Yakimova, R., Optical Biosensors Based on ZnO Nanostructures: Advantages and Perspectives. A Review. Sens. Actuator B-Chem. 2016, 229, 664-677.

8. Viter, R.; Abou Chaaya, A.; Iatsunskyi, I.; Nowaczyk, G.; Kovalevskis, K.; Erts, D.; Miele, P.; Smyntyna, V.; Bechelany, M., Tuning of ZnO 1D Nanostructures by Atomic Layer Deposition and Electrospinning for Optical Gas Sensor Applications. Nanotechnology 2015, 26, 105501.

9. Joshi, B. N.; Yoon, H.; Na, S.-H.; Choi, J.-Y.; Yoon, S. S., Enhanced Photocatalytic Performance of Graphene-ZnO Nanoplatelet Composite Thin Films Prepared by Electrostatic Spray Deposition. Ceram. Int. 2014, 40, 3647-3654.

10. Mao, S.; Cui, S.; Yu, K.; Wen, Z.; Lu, G.; Chen, J., Ultrafast Hydrogen Sensing Through Hybrids of Semiconducting Single-Walled Carbon Nanotubes and Tin Oxide Nanocrystals. Nanoscale 2012, 4, 1275-1279.

11. Dutta, M.; Sarkar, S.; Ghosh, T.; Basak, D., ZnO/Graphene Quantum Dot Solid-State Solar Cell. J. Phys. Chem. C 2012, 116, 20127-20131.

12. Liu, F.; Zhang, Y.; Yu, J.; Wang, S.; Ge, S.; Song, X., Application of ZnO/Graphene and S6 Aptamers for Sensitive Photoelectrochemical Detection of SK-BR-3 Breast Cancer Cells Based on a Disposable Indium Tin Oxide Device. Biosens. Bioelectron. 2014, 51, 413420.

13. Son, D. I.; Kwon, B. W.; Park, D. H.; Seo, W.-S.; Yi, Y.; Angadi, B.; Lee, C.-L.; Choi, W. K., Emissive ZnO-Graphene Quantum Dots for White-Light-Emitting Diodes. Nature Nanotech. 2012, 7, 465-471.

14. Singh, G.; Choudhary, A.; Haranath, D.; Joshi, A. G.; Singh, N.; Singh, S.; Pasricha, R., ZnO Decorated Luminescent Graphene as a Potential Gas Sensor at Room Temperature. Carbon 2012, 50, 385-394.

15. Wang, C.; Yin, L.; Zhang, L.; Xiang, D.; Gao, R., Metal Oxide Gas Sensors: Sensitivity and Influencing Factors. Sensors 2010, 10, 2088-2106.

16. Alver, U.; Zhou, W.; Belay, B.; Krueger, R.; Davis, K. O.; Hickman, N. S., Optical and Structural Properties of $\mathrm{ZnO}$ Nanorods Grown on Graphene Oxide and Reduced Graphene Oxide Film by Hydrothermal Method. Appl. Surf. Sci. 2012, 258, 3109-3114.

17. Faÿ, S.; Shah, A., Zinc Oxide Grown by CVD Process as Transparent Contact for Thin Film Solar Cell Applications. In Transparent Conductive Zinc Oxide: Basics and Applications in Thin Film Solar Cells, Ellmer, K.; Klein, A.; Rech, B., Eds. Springer Berlin Heidelberg: Berlin, Heidelberg, 2008, 235-302. 
18. Ding, J.; Yan, X.; Xue, Q., Study on Field Emission and Photoluminescence Properties of ZnO/Graphene Hybrids Grown on Si Substrates. Mater. Chem. Phys. 2012, 133, 405-409.

19. Ismail, A.; Abdullah, M. J., The structural and Optical Properties of ZnO Thin Films Prepared at Different RF Sputtering Power. J. King Saud Univ. Sci. 2013, 25, 209-215.

20. Ding, J.; Wang, M.; Deng, J.; Gao, W.; Yang, Z.; Ran, C.; Zhang, X., A Comparison Study Between ZnO Nanorods Coated with Graphene Oxide and Reduced Graphene Oxide. $J$. Alloy. Comp. 2014, 582, 29-32.

21. Lu, T.; Zhang, Y.; Li, H.; Pan, L.; Li, Y.; Sun, Z., Electrochemical Behaviors of Graphene-ZnO and Graphene-SnO $\mathrm{S}_{2}$ Composite Films for Supercapacitors. Electrochim. Acta 2010, 55, 4170-4173.

22. Whitby, J. A.; Ostlund, F.; Horvath, P.; Gabureac, M.; Riesterer, J. L.; Utke, I.; Hohl, M.; Sedlacek, L.; Jiruse, J.; Friedli, V.; et al., High Spatial Resolution Time-of-Flight Secondary Ion Mass Spectrometry for the Masses: A Novel Orthogonal ToF FIB-SIMS Instrument with In Situ AFM. Adv. Mater. Sci. Eng. 2012, 2012, 180437.

23. Abou Chaaya, A.; Viter, R.; Bechelany, M.; Alute, Z.; Erts, D.; Zalesskaya, A.; Kovalevskis, K.; Rouessac, V.; Smyntyna, V.; Miele, P., Evolution of Microstructure and Related Optical Properties of $\mathrm{ZnO}$ grown by Atomic Layer Deposition. Beilstein J. Nanotechnol. 2013, 4, 690-698.

24. George, S. M., Atomic Layer Deposition: An Overview. Chem. Rev. 2010, 110, 111131.

25. Hernandez, Y.; Nicolosi, V.; Lotya, M.; Blighe, F. M.; Sun, Z.; De, S.; McGovern, I. T.; Holland, B.; Byrne, M.; et al., High-Yield Production of Graphene by Liquid-Phase Exfoliation of Graphite. Nature Nanotech. 2008, 3, 563-568.

26. Loryuenyong, V.; Totepvimarn, K.; Eimburanapravat, P.; Boonchompoo, W.; Buasri, A., Preparation and Characterization of Reduced Graphene Oxide Sheets via Water-Based Exfoliation and Reduction Methods. Adv. Mater. Sci. Eng. 2013, 2013, 923403.

27. First, P. N.; de Heer, W. A.; Seyller, T.; Berger, C.; Stroscio, J. A.; Moon, J.-S., Epitaxial Graphenes on Silicon Carbide. MRS Bull. 2010, 35, 296-305.

28. Yao, Y.; Li, Z.; Lin, Z.; Moon, K.-S.; Agar, J.; Wong, C., Controlled Growth of Multilayer, Few-Layer, and Single-Layer Graphene on Metal Substrates. J. Phys. Chem. C 2011, 115, 5232-5238.

29. Kavitha, T.; Gopalan, A. I.; Lee, K.-P.; Park, S.-Y., Glucose Sensing, Photocatalytic and Antibacterial Properties of Graphene-ZnO Nanoparticle Hybrids. Carbon 2012, 50, 29943000 .

30. Jiao, K.; Wu, X.; Duan, C.; Zhang, D.; Wang, Y.; Chen, Y., Novel ALD-Assisted Growth of $\mathrm{ZnO}$ Nanorods on Graphene and its $\mathrm{Cu}_{2} \mathrm{ZnSn}\left(\mathrm{S}_{\mathrm{x}} \mathrm{Se}_{1-\mathrm{x}}\right)_{(4)}$ Solar Cell Application. Phys. Chem. Chem. Phys. 2015, 17, 4757-4762.

31. Lin, J.-C.; Huang, B.-R.; Lin, T.-C., Hybrid Structure of Graphene Sheets/ZnO Nanorods for Enhancing Electron Field Emission Properties. Appl. Surf. Sci. 2014, 289, 384387.

32. Viter, R.; Iatsunskyi, I.; Fedorenko, V.; Tumenas, S.; Balevicius, Z.; Ramanayicius, A.; Balme, S.; Kempinski, M.; Nowaczyk, G.; Jurga, S.; el al., Enhancement of Electronic and Optical Properties of $\mathrm{ZnO} / \mathrm{Al}_{2} \mathrm{O}_{3}$ Nanolaminate Coated Electrospun Nanofibers. J. Phys. Chem. C 2016, 120, 5124-5132.

33. Mattevi, C.; Kim, H.; Chhowalla, M., A Review of Chemical Vapour Deposition of Graphene on Copper. J. Mater. Chem. 2011, 21, 3324-3334.

34. Ghoneim, M. T.; Smith, C. E.; Hussain, M. M., Simplistic Graphene Transfer Process and its Impact on Contact Resistance. Appl. Phys. Lett. 2013, 102, 183115. 
35. Bachmann, J.; Zierold, R.; Chong, Y. T.; Hauert, R.; Sturm, C.; Schmidt-Grund, R.; Rheinlaender, B.; Grundmann, M.; Goesele, U.; Nielsch, K., A Practical, Self-catalytic, Atomic Layer Deposition of Silicon Dioxide. Angew. Chem. Int. Ed. 2008, 47, 6177-6179.

36. Iatsunskyi, I.; Coy, E.; Viter, R.; Nowaczyk, G.; Jancelewicz, M.; Baleviciute, I.; Zaleski, K.; Jurga, S., Study on Structural, Mechanical, and Optical Properties of $\mathrm{Al}_{2} \mathrm{O}_{3}-\mathrm{TiO}_{2}$ Nanolaminates Prepared by Atomic Layer Deposition. J. Phys. Chem. C 2015, 119, 2059120599.

37. Hybertsen, M. S.; Louie, S. G., First-Principles Theory for the Quasiparticle Energies of Semiconductors and Insulators. Phys. Rev. Lett. 1985, 55, 1418-1421.

38. Klingshirn, C., Introduction. In Zinc Oxide: From Fundamental Properties Towards Novel Applications, Springer Berlin Heidelberg: Berlin, Heidelberg, 2010, 1-6.

39. Xu, P.; Tang, Q.; Zhou, Z., Structural and Electronic Properties of Graphene-ZnO Interfaces: Dispersion-Corrected Density Functional Theory Investigations. Nanotechnology 2013, 24, 305401 .

40. Stoev, K.; Sakurai, K., Recent Theoretical Models in Grazing Incidence X-ray Reflectometry. Rigaku J. 1997, 14, 22-37.

41. Seo, T. H.; Lee, S.; Cho, H.; Chandramohan, S.; Suh, E.-K.; Lee, H. S.; Bae, S. K.; Kim, S. M.; Park, M.; Lee, J. K.; Kim, M. J., Tailored CVD Graphene Coating as a Transparent and Flexible Gas Barrier. Sci. Rep. 2016, 6, 24143.

42. Malard, L. M.; Pimenta, M. A.; Dresselhaus, G.; Dresselhaus, M. S., Raman Spectroscopy in Graphene. Phys. Rep. 2009, 473, 51-87.

43. Kudin, K. N.; Ozbas, B.; Schniepp, H. C.; Prud'homme, R. K.; Aksay, I. A.; Car, R., Raman Spectra of Graphite Oxide and Functionalized Graphene Sheets. Nano Lett. 2008, 8, 36-41.

44. Wu, W.; Yu, Q.; Peng, P.; Liu, Z.; Bao, J.; Pei, S.-S., Control of Thickness Uniformity and Grain Size in Graphene Films for Transparent Conductive Electrodes. Nanotechnology 2012, 23, 035603.

45. Luo, Z.; Lu, Y.; Singer, D. W.; Berck, M. E.; Somers, L. A.; Goldsmith, B. R.; Johnson, A. T. C., Effect of Substrate Roughness and Feedstock Concentration on Growth of Wafer-Scale Graphene at Atmospheric Pressure. Chem. Mater. 2011, 23, 1441-1447.

46. Shin, K.-S.; Jo, H.; Shin, H.-J.; Choi, W. M.; Choi, J.-Y.; Kim, S.-W., High Quality Graphene-Semiconducting Oxide Heterostructure for Inverted Organic Photovoltaics. $J$. Mater. Chem. 2012, 22, 13032-13038.

47. Beams, R.; Cancado, L. G.; Novotny, L., Raman Characterization of Defects and Dopants in Graphene. J. Phys. Condens. Matter 2015, 27, 083002.

48. Si, C.; Sun, Z.; Liu, F., Strain Engineering of Graphene: a Review. Nanoscale 2016, 8, 3207-3217.

49. Iqbal, M. W.; Iqbal, M. Z.; Khan, M. F.; Jin, X.; Hwang, C.; Eom, J., Modification of the Structural and Electrical Properties of Graphene Layers by Pt Adsorbates. Sci. Technol. Adv. Mater. 2014, 15, 055002.

50. Abou Chaaya, A.; Viter, R.; Baleviciute, I.; Bechelany, M.; Ramanavicius, A.; Gertnere, Z.; Erts, D.; Smyntyna, V.; Miele, P., Tuning Optical Properties of $\mathrm{Al}_{2} \mathrm{O}_{3} / \mathrm{ZnO}$ Nanolaminates Synthesized by Atomic Layer Deposition. J. Phys. Chem. C 2014, 118, $3811-$ 3819.

51. Ozerov, I.; Arab, M.; Safarov, V. I.; Marine, W.; Giorgio, S.; Sentis, M.; Nanai, L., Enhancement of Exciton Emission from $\mathrm{ZnO}$ Nanocrystalline Films by Pulsed Laser Annealing. Appl. Surf. Sci. 2004, 226, 242-248.

52. Reynolds, D. C.; Look, D. C.; Jogai, B.; Collins, T. C., Polariton and Free-ExcitonLike Photoluminescence in ZnO. Appl. Phys. Lett. 2001, 79, 3794-3796. 
53. Raghavan, R.; Bechelany, M.; Parlinska, M.; Frey, D.; Mook, W. M.; Beyer, A.; Michler, J.; Utke, I., Nanocrystalline-to-Amorphous Transition in Nanolaminates Grown by Low Temperature Atomic Layer Deposition and Related Mechanical Properties. Appl. Phys. Lett. 2012, 100, 191912.

54. Viter, R.; Baleviciute, I.; Abou Chaaya, A.; Mikoliunaite, L.; Balevicius, Z.; Ramanavicius, A.; Zalesska, A.; Vatamana, V.; Smyntyna, V.; Gertnere, et al., Optical Properties of Ultrathin $\mathrm{Al}_{2} \mathrm{O}_{3} / \mathrm{ZnO}$ Nanolaminates. Thin Solid Films 2015, 594, 96-100.

55. Chang, Y.-C.; Liu, C.-H.; Liu, C.-H.; Zhang, S.; Marder, S. R.; Narimanov, E. E.; Zhong, Z.; Norris, T. B., Realization of Mid-infrared Graphene Hyperbolic Metamaterials. Nat Commun. 2016, 7, 10568.

56. Seo, H.-K.; Park, M.-H.; Kim, Y.-H.; Kwon, S.-J.; Jeong, S.-H.; Lee, T.-W., Laminated Graphene Films for Flexible Transparent Thin Film Encapsulation. ACS Appl. Mater. Interfaces 2016, 8, 14725-14731.

57. Malekpour, H.; Chang, K. H.; Chen, J. C.; Lu, C. Y.; Nika, D. L.; Novoselov, K. S.; Balandin, A. A., Thermal Conductivity of Graphene Laminate. Nano Lett. 2014, 14, 51555161. 


\section{FIGURES}

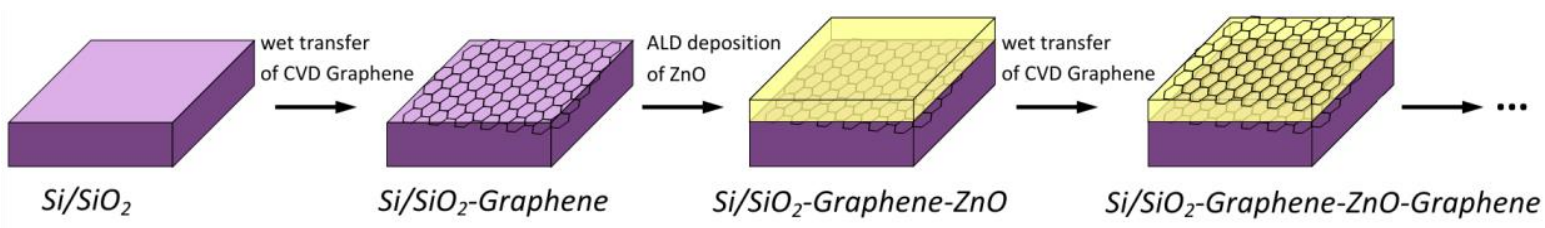

Figure 1.Schematic representation of fabrication of $\mathrm{G} / \mathrm{ZnO}$ nanolaminates by alternating

$\mathrm{ZnO}$ deposition and graphene transfer.
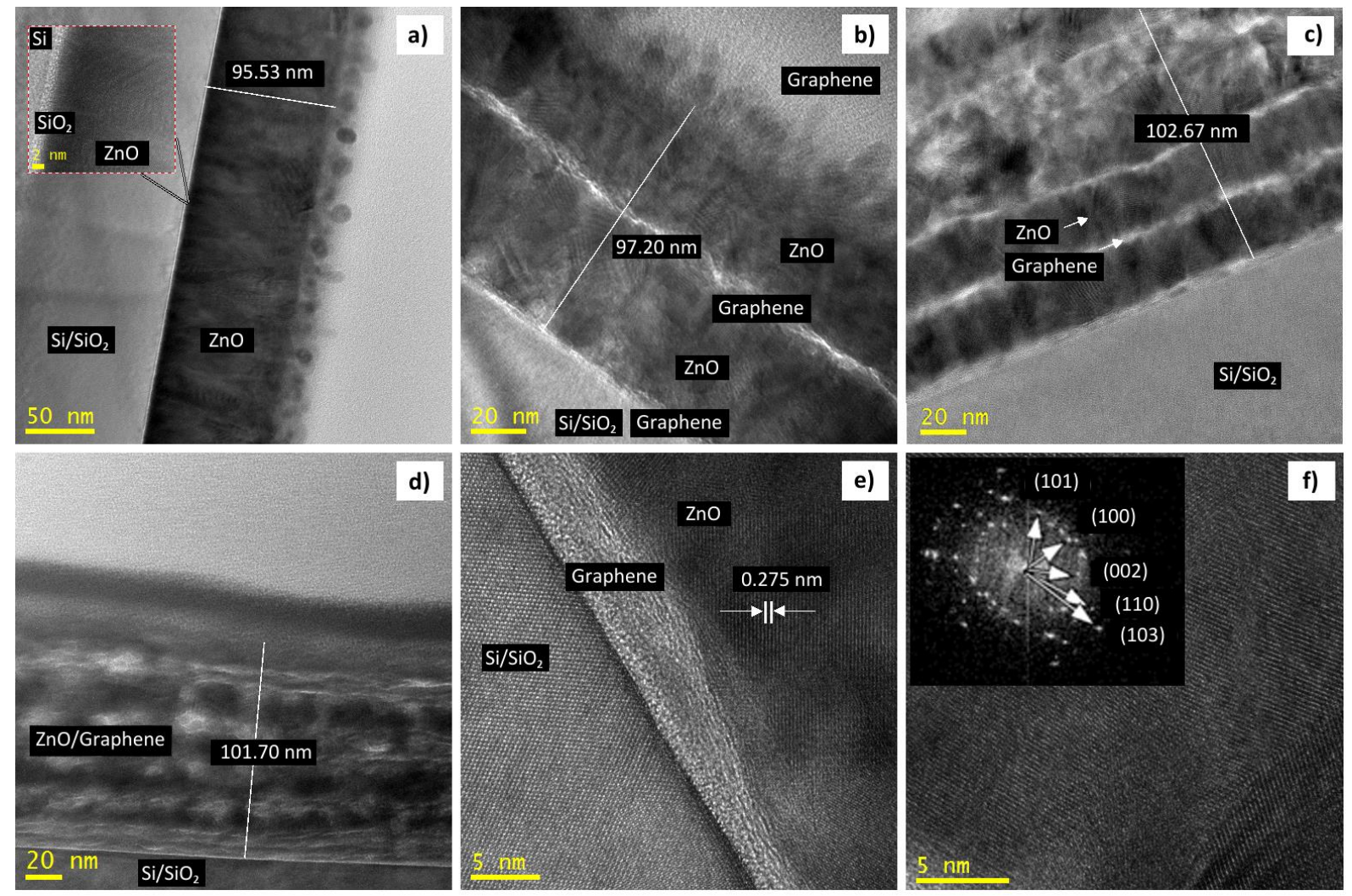

Figure 2.TEM images of cross-section of pure $\mathrm{ZnO}$ layer (a) and Graphene/ZnO nanolaminates with different number of graphene layers: b) $\left.G_{3 L} \mathrm{ZnO}_{50 n m}, c\right) G_{5 L} \mathrm{ZnO}_{25 n m}$, d) $G_{11 L} \mathrm{ZnO}_{10 n m}$, (e) interface of $\mathrm{Si}_{\mathrm{SiO}}$-Graphene-ZnO, f) interlayer of $\mathrm{ZnO}$ of the sample $G_{11 L} \mathrm{ZnO}_{10 n m}$ and FFT of this area. 

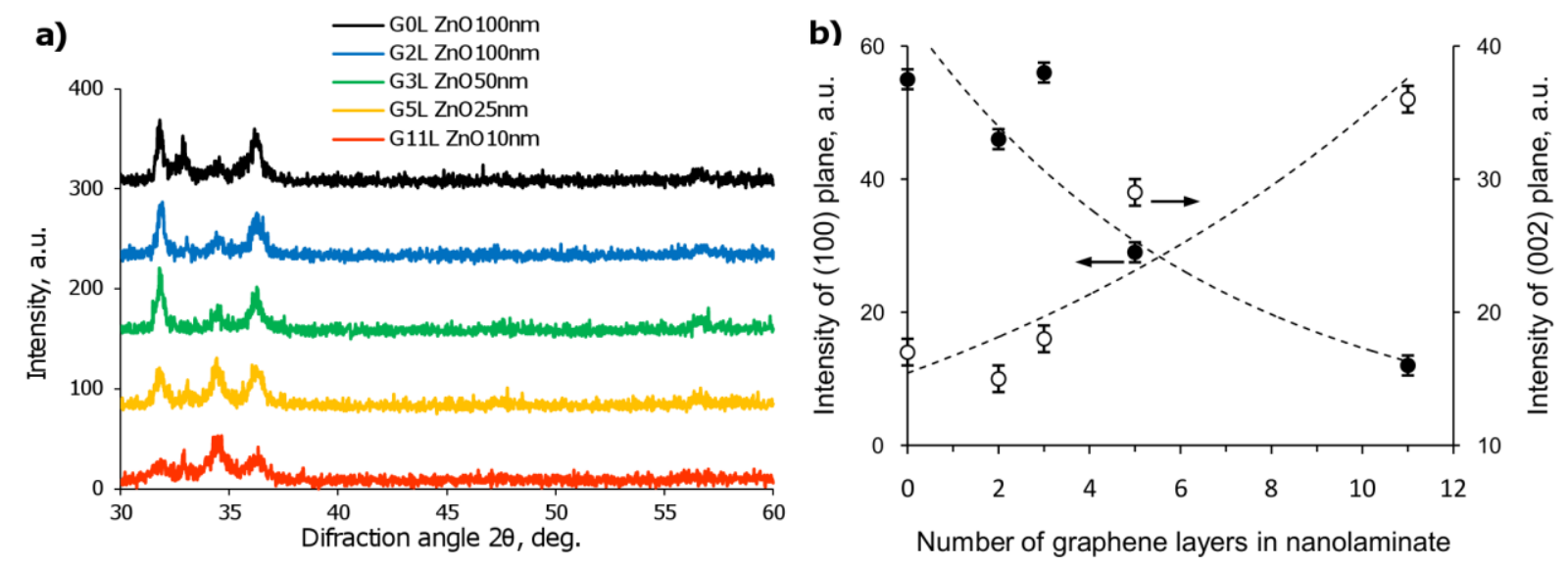

Figure 3.X-ray diffraction patterns of $\mathrm{ZnO}$ thin film and Graphene/ZnO nanolaminates (a) and curves illustrating intensities of diffraction peaks of (100) plane (closed symbols, primary scale) and of (002) plane (open symbols, secondary scale) vs number of graphene layers in the $G / Z n O$ nanolaminates $(b)$
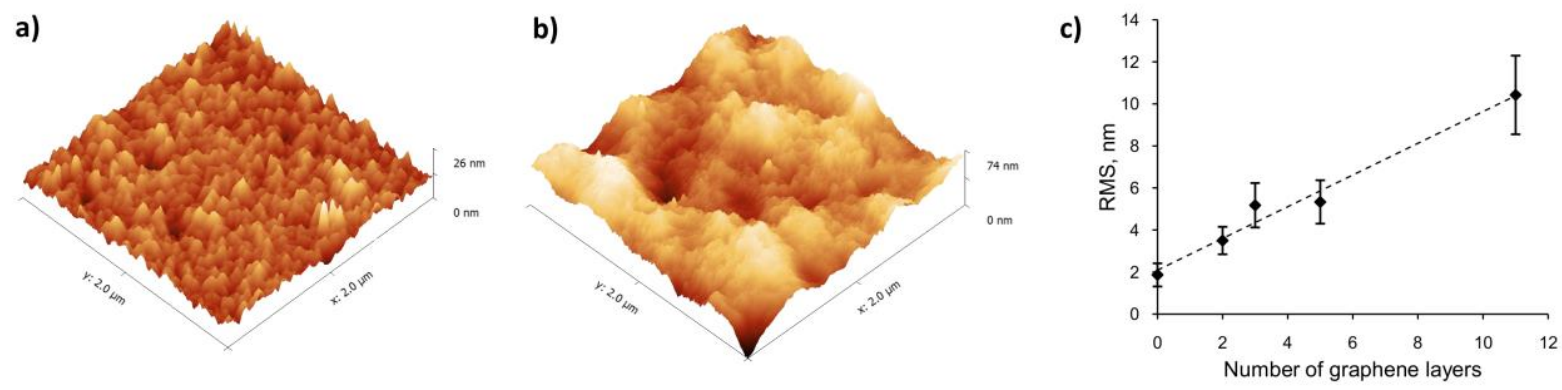

Figure 4.AFM images of the surface of Graphene/ZnO nanolaminates with 2 graphene layers: $G_{2 L} Z n n_{100 n m}(a)$, with 11 graphene layers $G_{11 L} Z n O_{10 n m}(b)$ and the dependence of number of graphene layers to surface roughness of $100 \mathrm{~nm}$ thick Graphene/ZnO nanolaminates (c). 


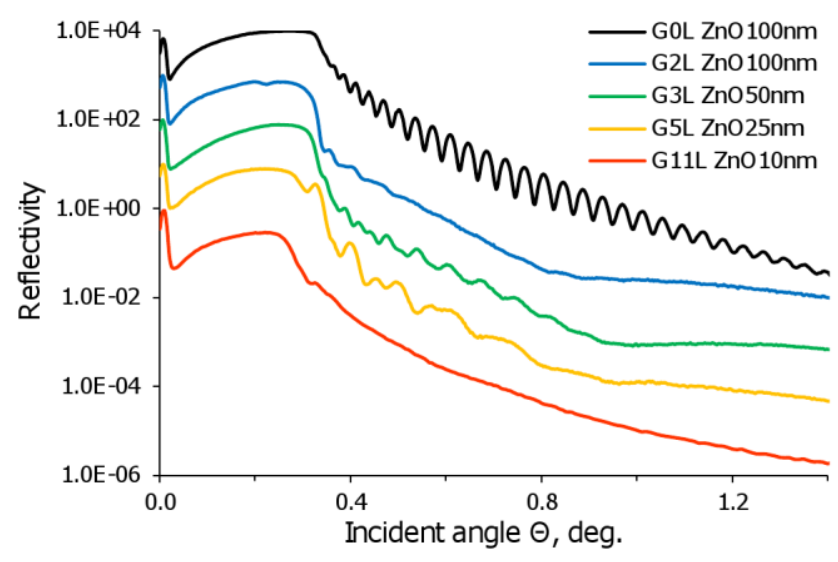

Figure 5. X-ray reflectivity profiles of $\mathrm{ZnO}$ thin film and Graphene/ZnO nanolaminates.
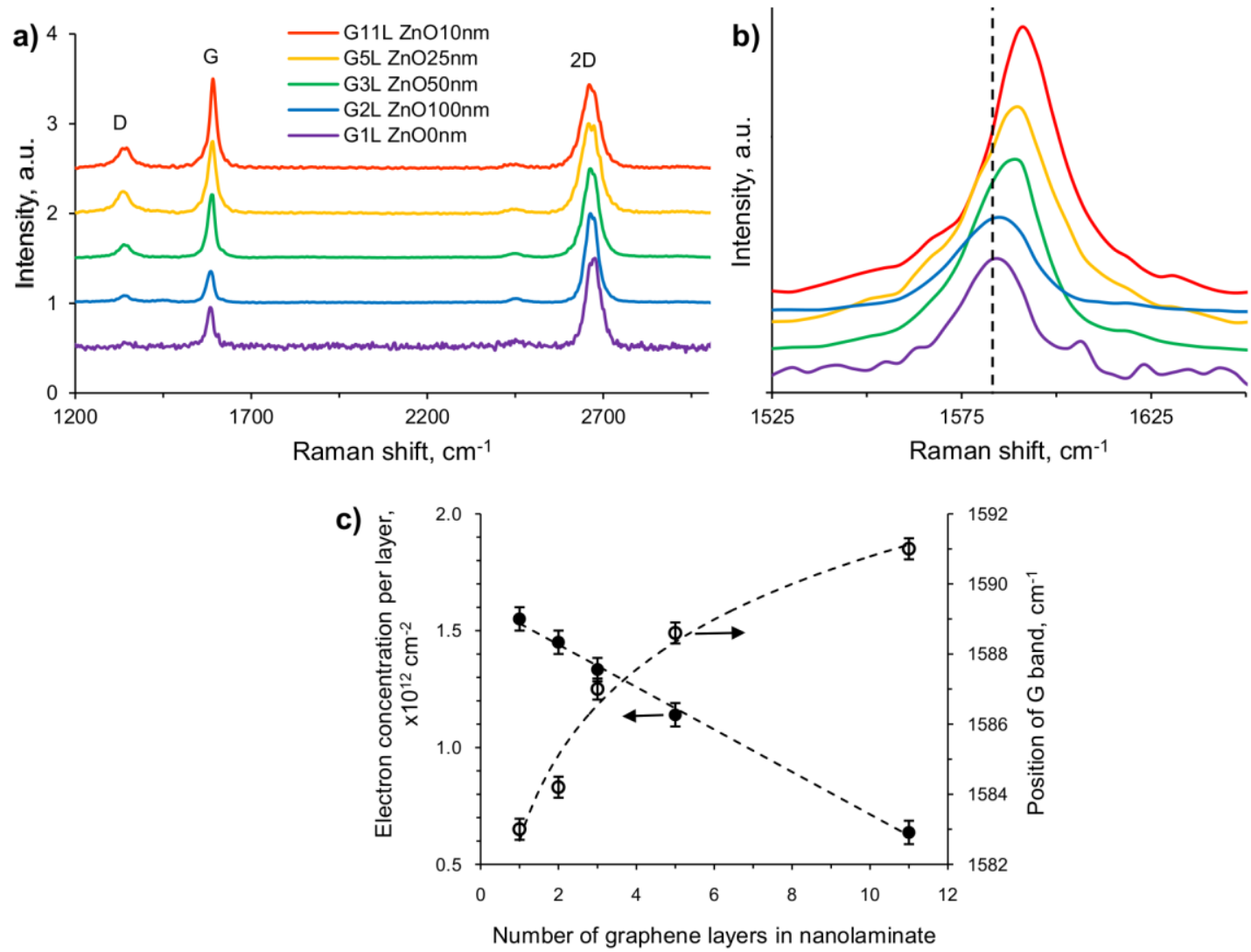

Figure 6.Raman spectra of graphene and Graphene/ZnO nanolaminates (a), close view of $G$ band shifting (b), and curves illustrating shifting of $G$ band (open symbols, secondary scale) and charge per graphene layer (closed symbols, primary scale) vs number of graphene layers in the $G / \mathrm{ZnO}$ nanolaminates (c) 

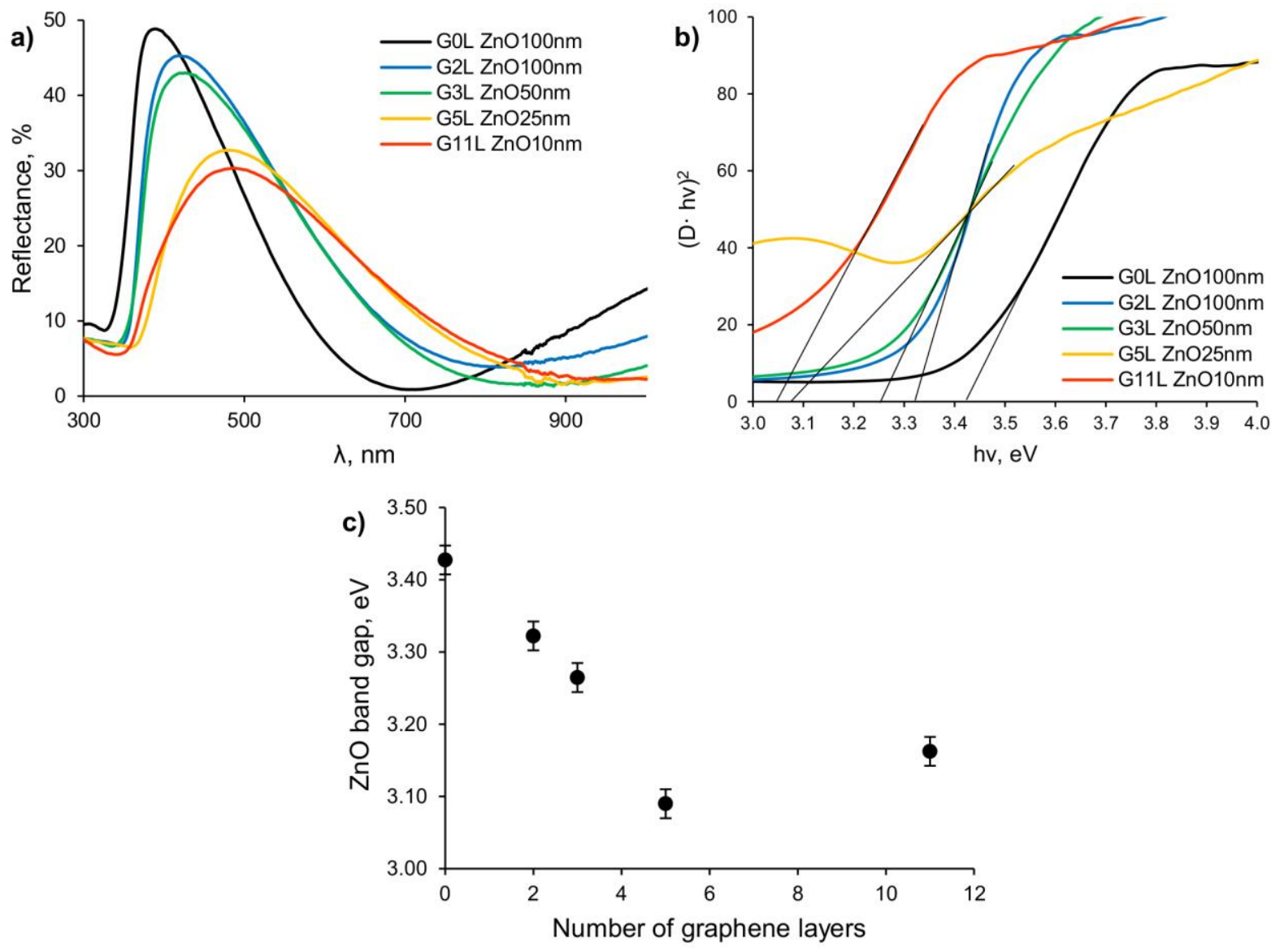

Figure 7. Reflectance spectra (a), band gap calculation on the absorption edge from reflectance spectra (b) and dependence of the $\mathrm{ZnO}$ band gap on the number of graphene layers (c) of $\mathrm{ZnO}$ thin film and Graphene/ZnO nanolaminates.
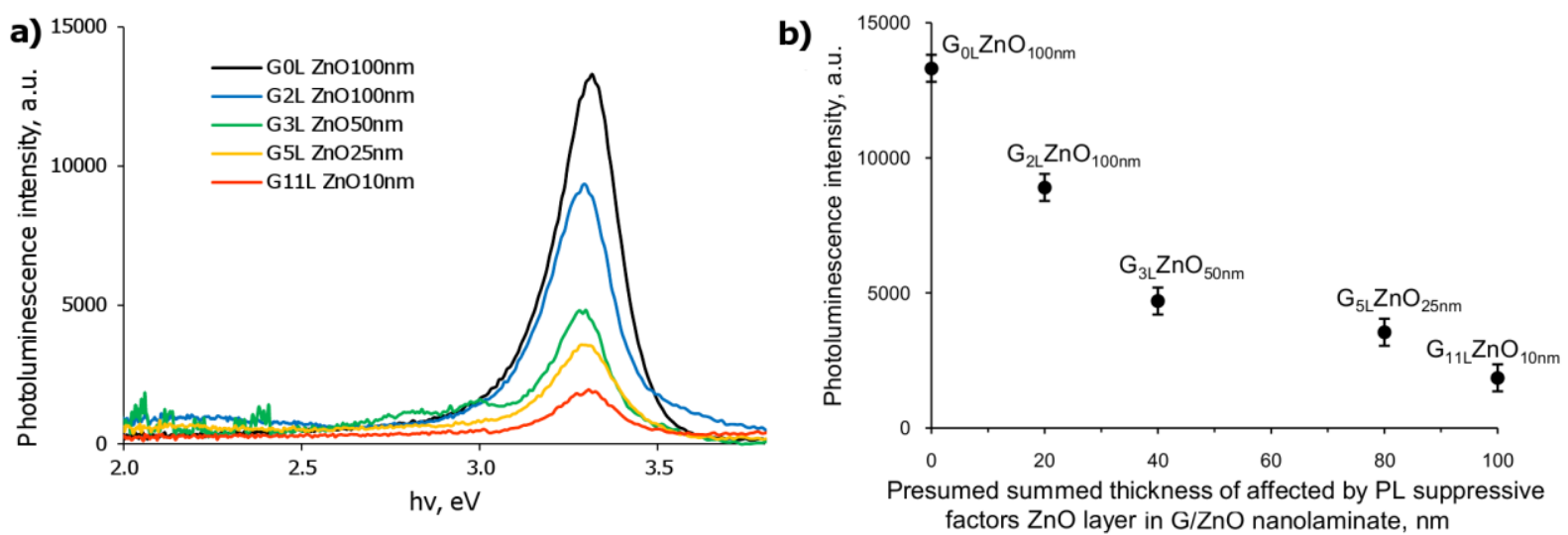

Figure 8.Photoluminescence spectra of $\mathrm{ZnO}$ thin film and Graphene/ZnO nanolaminates (a),

Graphene/ZnO nanolaminate photoluminescence intensity vs. presumed summed thickness of 
ZnO layer affected by $P L$ suppressive factors in $\mathrm{G} / \mathrm{ZnO}$ (calculated assuming $10 \mathrm{~nm}$ thick

ZnO layers affected by PL suppressive factors near the every surface of individual graphene layers). 


\section{TABLES}

Table 1. Ratio of bands intensities of single graphene layer and Graphene/ZnO nanolaminates calculated from Raman spectra; Measurement deviation is calculated from the TEM images.

\begin{tabular}{|c|c|c|c|c|c|c|}
\hline Sample & $\begin{array}{l}\text { Schematic } \\
\text { representation }\end{array}$ & $\begin{array}{l}\text { Thickness of } \\
\text { each } \quad \mathrm{ZnO} \\
\text { interlayer }(\mathrm{nm})\end{array}$ & $\begin{array}{l}\text { Number of } \\
\text { graphene } \\
\text { layers }\end{array}$ & $\begin{array}{l}\text { Number of } \\
\mathrm{ZnO} \text { layers }\end{array}$ & $\mathrm{I}_{2 \mathrm{D}} / \mathrm{I}_{\mathrm{G}}$ & $\mathrm{I}_{\mathrm{D}} / \mathrm{I}_{\mathrm{G}}$ \\
\hline $\mathrm{G}_{0 \mathrm{~L}} \mathrm{ZnO}_{100 \mathrm{~nm}}$ & & $100 \pm 5$ & 0 & 1 & - & - \\
\hline $\mathrm{G}_{1 \mathrm{~L}} \mathrm{ZnO}_{0 \mathrm{~nm}}$ & & - & 1 & 0 & 2.18 & 0.1 \\
\hline $\mathrm{G}_{2 \mathrm{~L}} \mathrm{ZnO}_{100 \mathrm{~nm}}$ & & $100 \pm 5$ & 2 & 1 & 2.68 & 0.22 \\
\hline $\mathrm{G}_{3 \mathrm{~L}} \mathrm{ZnO}_{50 \mathrm{~nm}}$ & & $50 \pm 1.4$ & 3 & 2 & 1.33 & 0.20 \\
\hline $\mathrm{G}_{5 \mathrm{~L}} \mathrm{ZnO}_{25 \mathrm{~nm}}$ & & $25 \pm 0.5$ & 5 & 4 & 1.20 & 0.24 \\
\hline $\mathrm{G}_{11 \mathrm{~L}} \mathrm{ZnO}_{10 \mathrm{~nm}}$ & & $10 \pm 0.3$ & 11 & 10 & 0.87 & 0.21 \\
\hline
\end{tabular}

TOC FIGURE

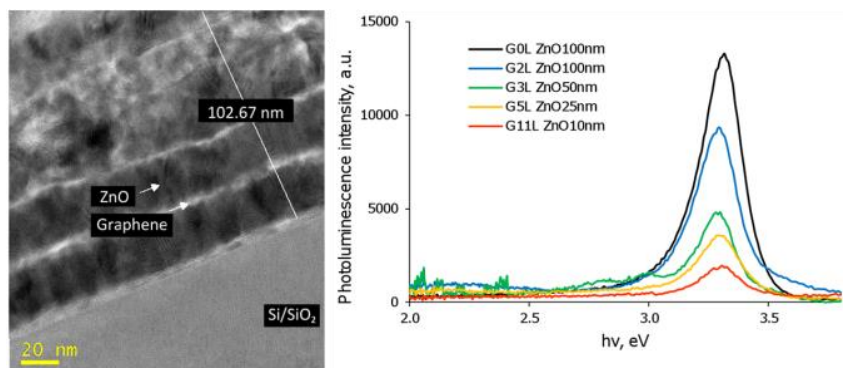

